\title{
Does Parental Financial Communication Affect Emerging Adults' Financial Behavior?
}

\author{
Muhammad Andi Abdillah Triono ${ }^{1}$, Syahrizal Chalil Dalimunthe ${ }^{2}$, Humisar Sihombing ${ }^{3}$ \\ \{andiabdillah@unimed.ac.id ${ }^{1 *}$, cokichrp@yahoo.com², hisarnababan17@gmail.com ${ }^{3}$ \} \\ 1,2,3 Universitas Negeri Medan, Indonesia \\ *andiabdillah@unimed.ac.id
}

\begin{abstract}
This study focuses on investigating the relation between parental financial communication and financial behavior in emerging adults, an issue which most studies have less intention in the current literature. Primary data were used with a cohort of university students that taken financial courses in 2019/2020 academics year in State University of Medan with total sample $(n=241)$ to develop a pathways model of parental financial communication towards emerging adults Financial Behavior. The sample participants ranged from 18 to 25 years old. The finding confirms the existence of parental financial communication relationship towards the development of emerging adults' financial behavior. More importantly, direct financial communication reveals significant in reflecting parental financial communication as latent variable rather than indirect financial communication. Moreover, direct parental financial communication trigger general management and capital accumulation management as a reflection of the development of emerging adults' financial behavior as latent variable.
\end{abstract}

Keywords: Emerging Adults, Parental Financial Communication, Financial Behavior

\section{Introduction}

A unique transitional stage in development between near total dependence on family adolescence and near total independence is represented by the emerging adult's population [1] with range of age 18 to 25 years old [2,3,4], which financial independence is one key indicator of a successful transition to adulthood [3]. Nevertheless, a significant source of stress for college students is deal in financial strain, that could raise the risks of depression and other mental health problems and lowers the probability of graduating from college if it not manage in proper $[5, \mathrm{p}$. 453]. Moreover, S.L. Worthy, et al. [2] characterized emerging adults as an individual that has less stable: financial situation, interpersonal relationships, living arrangements, cognitive and emotional development, and religious beliefs than adults. Furthermore, studies about emerging adults financial behavior found that lack adequate financial knowledge, poor financial decisions and engage in more risk-taking behaviors are related to most of emerging adults $[2,6]$. A study that has been done by B. L. Jorgensen, et al [1] in examine the emerging adults financial behavior base 
on family financial socialization theory with 321 sample of college students found that financial communication and locus of control mediated the relationship between attachment insecurity and financial behavior. In addition, S. L. Worthy, et al. [2] found that age, gender, public assistance, adults status, sensation seeking, and potential for problem gambling were related to student financial behavior. S. Shim, et al. [3] study revealed that parental socialization has significant role in changing individuals' financial attitude, financial controllability, and financial efficacy. No study was found in Indonesia emerging adults that focusing relationship between parental financial communication and financial behavior. This study is unique in its exertion to determine how parental financial communication and emerging adults' financial behavior are reflectively construct in a line of model. Therefore, this study examined relationship between parental financial communication and financial behavior of emerging adults.

Parental financial communication is part of purposive financial socialization [1], which is defined by C. G. Gudmunson and S. M. Danes [7] as efforts of family members in financially socialize each other intentionally. Study that has been done by N. Tang, A. Baker and P. C. Peter [8] showed that parental influence and self-discipline positively correlate with responsible financial behavior. Moreover, a study that has been done by U. Sirsch, M. Zupanc `ic ic et al. [9] with Austrians and Slovens university students as their sample revealed that there is significant links between adopting parental role model and financial behavior control. However, a study showed that parental control in psychologically had a direct effect on emerging adults' risky behavior, decrease life satisfaction, self-esteem and endorsement [10]. Furthermore, Pinto et al. in C. G. Gudmunson and S. M. Danes [7, p. 650] revealed that college students receive more information about credit from parents than from peers, media or school and that the more information they receive from parent, the lower are their credit card balances. B. L. Jorgensen et al. [1] found that emerging adults' financial behavior has been affected by parental financial communication, which was assessed through emerging adult perceptions of parental direct (e.g. discussion and teaching) and indirect (e.g. modeling) communication.

C. G. Gudmunson and S. M. Danes [7, p. 650] describe two types of financial behavior. First type is common definition of financial behavior which expresses a frequently pattern of action such as earning, saving, spending, and gifting. The second type relates to financial turning points and decision making. Furthermore, B. L. Jorgensen et al. [1] define financial behavior in the domains of cash management, credit management, capital accumulation, and general management. Moreover, N. Tang and A. Baker [11] revealed of their study on financial knowledge and financial behavior among average house hold in Europe, the United State, Australia, and other countries that there is significant direct and indirect association between self-esteem and individual financial behavior after have a hold over financial knowledge and other socioeconomic factors.

In light of the pressing nature of this topic, this article makes the following contribution. First, factual definitions of parental financial communication and emerging adults through constructs measurement assessment of its' confirmatory indicators. Secondly, obtaining the path value between parental financial communication and emerging adults' financial behavior. Finally, synthesis the result of construct measurement and path measurement. Moreover, the main focus of this study is to examine the financial behavior of emerging adults and their relationship with their parents. 


\section{Literature Review}

\subsection{Parental Financial Communication}

As it was mention in B. L. Jorgensen et al. [1] that parental financial communication is a segment of purposive financial socialization that is defined by C. G. Gudmunson and S. M. Danes [7, p. 649] as "intentional efforts family members use to financially socialize each other". Furthermore, B. L. Jorgensen et al. [1] constructs definition that derived from C. G. Gudmunson and S. M. Danes [7, p. 649] and B. L. Jorgensen and J. Savla [6] as emerging adults perceptions of parental direct (e.g., discussion and teaching) and indirect financial communication (e.g., modeling).

\subsection{Financial Behavior}

Financial behavior examines the decision making of individual, including cognitive and emotional biases, which based on perceptiveness in explaining individual behavior, market inefficiencies, and stocks anomaly [12]. B. L. Jorgensen et al. [1] define financial behavior in the domains of cash management, credit management, capital accumulation, and general management. Furthermore, C. G. Gudmunson and S. M. Danes [7, p. 650] describe two types of financial behavior. First type is common definition of financial behavior which expresses a frequently pattern of action such as earning, saving, spending, and gifting. The second type relates to financial turning points and decision making.

The central focus of the current study was the nature of the relationship between parental financial communication and emerging adults' financial behavior. Consistent with the model proposed by B. L. Jorgensen [1], this study was hypothesized in three stages. Firstly, parental financial communication as an exogenus and also latent variable was hypothesized with two indicators which is direct parental financial communication and indirect parental financial communication. Secondly, emerging adults' financial behavior as an endogenus and also latent varibles was hypothesized with four indicators which is cash management, credit management, capital accumulation, and general mangement. Lastly, the path value between parental financial communication and emerging adults' financial behavior was hypothesized.

In summary, the research hypotheses are:

H1 Parental financial communication could be explained by direct and indirect parental financial communication.

H2 Emerging adults' financial behavior could be explianed by cash management, credit management, capital accumulation, and general management.

H3 Emerging adults' financial bahvior could be affected by parental financial communication.

\section{Research Method}

This study is explorative study and has been carried out from $1^{\text {st }}$ of August until $16^{\text {th }}$ November 2019. Furthermore, sample were taken from undergraduate students with a total of 241 respondent that were identified as emerging adults with age range from 18 to 25 years old. Purposive sampling technique were used with a chriteria of age and must be registered in financial 
coureses from 1 August 2019 in 2019/2020 academic year at Management Department Program State University of Medan. Nonparamatric statistics were used and all data and hypotheses were analyzed through structural equation modeling partial least square with the help pf Smart PLS 3.0 application.

Parental financial communication as latent variable was measured through two indicators which is direct and indirect parental financial. In consistent with the model and measurement assessment scale that has been modeled by B. L. Jorgensen [1], each indicator has fifteen items of statement that evaluate budgeting, developing credit rating, and health insurance. The items were four-point Likert-type responses ranging from one to four with one represented by "Never" and four by "Always," the higher the score represent more frequent parental financial communication.

Emerging adults' financial behavior construct was measured using four content indicators which is cash management, credit management, capital accumulation, and general mangement. The four indicators was measured consistent with the model and measurement assessment scale that has been modeled by N. M. Porter [13] and B. L. Jorgensen [1]. The cash mangement scale contained three items with four-point Likert-type responses examining behavior related to managing one's cash reserves (e.g., "I used a weekly/monthly budget to track my income and expenses."). The credit management scale contained a total of four questions, though only two were four-point Likert-type responses. The other two items realted to pay-day loan usage and credit card possession were five and seven-point Likert-type items, respectively. The capital accumulation scale was comprised of two five-point Likert- type items ranging from on to five, with one represented by "Never" and five by "Always". These items examined saving and investment bahvior. Lastly, the general management scale was comprised of three four-point Likert-type questions related to long term planning and continuous assessment of overall financial status. Responses ranged from one to four with one represented as "Never" and four represented as "Always."

Based on measurement that has been described, the statistical equation for this study are:

1. Parental financial communication construct(Outter Model - $\xi$ ):

$$
\begin{aligned}
& x_{1}=\lambda_{1} \xi \ldots \ldots \ldots \ldots \text { Direct } \\
& x_{2}=\lambda_{2} \xi \ldots \ldots \ldots \ldots \text {. Indirect }
\end{aligned}
$$

2. Emerging adults' financial Behavior construct (Outter Model - $\eta$ ):

$$
\begin{array}{ll} 
& y_{1}=\lambda_{1} \eta \ldots \ldots \ldots \ldots . \text { General Management } \\
& y_{2}=\lambda_{2} \eta \ldots \ldots \ldots \ldots \text { Cash Management } \\
& y_{3}=\lambda_{3} \eta \ldots \ldots \ldots \ldots \text { Credit Management } \\
& y_{4}=\lambda_{4} \eta \ldots \ldots \ldots \ldots . \text { Capital Accumulation } \\
\text { 3. } & \text { Path (Inner Model) } \\
& \eta=\gamma \xi
\end{array}
$$

95 percent confidence interval was chosen for this study. Therefore, outer model could be justified as reliable if the value of AVE is more than 0.50 and the value of composite reliability and Cronbach alpha is more than 0.70. Furthermore, with significance level of 0.05 the path value or inner model must have T-statistics value more than 1.96 . 


\section{Results and Discussion}

Figure 1. showed that direct parental financial communication as reflective indicator has loading factor value 0.957 or more than 0.70 . However, indirect parental financial communication has loading factor value only 0.511 or less than 0.70 . Therefore, it is revealed that parental financial communication could only be reflected by direct communication rather than indirect communication. Furthermore, emerging adults' financial behavior is shown that only general management and capital accumulation with loading factor value 0.761 and 0.783 respectively. Consequently, emerging adults' financial behavior could be explained by general management and capital accumulation.

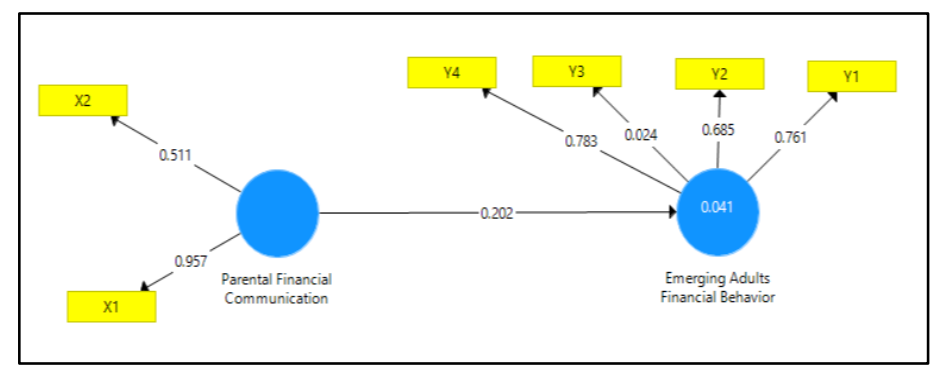

Fig 1. Construct Measurement

After eliminating all the indicators that value below 0.70 . The next step was to evaluate the path value and result showed that emerging adults' financial behavior is affected by parental financial communication with T-Statistics 3.774 or more than 1.96. Therefore, this enlighten the third hypotheses' which direct parental financial communication could trigger or affects general management and capital accumulation of emerging adults' financial behavior. In this case, the structural equation could be defined as $\eta=3.774 \xi$.

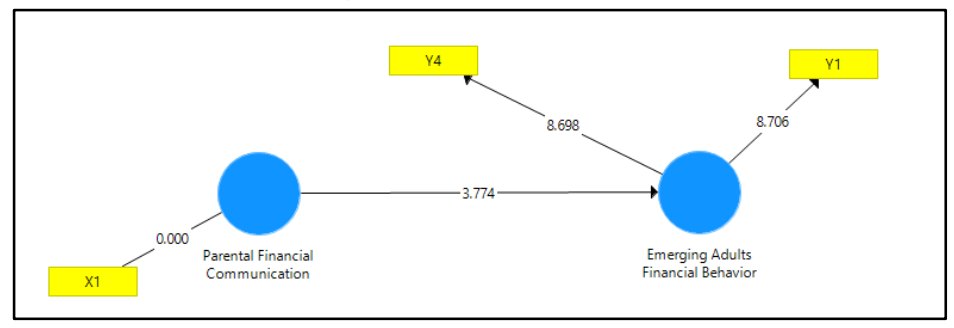

Fig 2. Structural Measurement

Construct and structural measurement in figure 1 and 2 revealed new perspective on emerging adults. This result is a case picture of emerging adults' financial behavior in a small cluster of university students in Department of Management Program State University of Medan which direct financial communication would be more prefer for emerging adults rather than indirect communication. This also indicates that general management and cash accumulation of 
student in Department Management Program could be trigger by direct parental financial communication. Although, not all indicators are significant, however, this outcome study is linear with the study result of B. L. Jorgensen [1] which direct parentel financial communication affects emerging adults financial behavior.

There are limitation that apply to the current study. First, the sample was to small which only apply on one university. Future studies should be examine this model with more wider area of sample. Secondly, the used of theories in supporting of this study is not indepth. Finally, the methodology need to be more advance in coping different demografic and environment.

\section{Conclusion}

The study used structural equation modeling partial least square to confirm part of B. L. Jorgensen [1] study in replicating its' to Department of Management Program State University of Medan. The results showed not all part that are replicated significantly proofen. Direct financial communication reveals significant in reflecting parental financial communication as latent variable rather than indirect financial communication. Moreover, direct parental financial communication trigger general management and capital accumulation management as a reflection of the development of emerging adults' financial behavior as latent variable.

\section{References}

[1] B. L. Jorgensen, D. L. Rappleyea, J. T. Schweichler, X. Fang and M. E. Moran, "The Financial Behavior of Emerging Adults: A Family Financial Socialization Approach," Journal of Family and Economic Issues, vol. 38, no. 1, p. 57-69, (2016).

[2] S. L. Worthy, J. Jonkman and L. Blinn-Pike, "Sensation-Seeking, Risk-Taking, and Problematic Financial Behaviors of College Students," Journal of Family and Economic Issues, vol. 31, no. 2, p. 161-170, (2010).

[3] S. Shim, J. Serido, C. Tang and N. Card, "Socialization processes and pathways to healthy financial development for emerging young adults," Journal of Applied Developmental Psychology, vol. 38, p. 29-38, (2015).

[4] J. L. Tanner and J. J. Arnett, "The emergence of 'emerging adulthood' The new life stage between adolescence and young adulthood," in Handbook of Youth and Young Adulthood, New York, Routledge, pp. 39-46, (2009).

[5] J. Serido, S. Shim, A. Mishra and C. Tang, "Financial Parenting, Financial Coping Behaviors, and Well-Being of Emerging Adults," Family Relation, vol. 59, no. 4, pp. 453-464, (2010).

[6] B. L. Jorgensen and J. Savla, "Financial Literacy of Young Adults: The Importance of Parental Socialization," Interdiciplinary Journal of Applied Family Studies, pp. 465-478, (2010). 
[7] C. G. Gudmunson and S. M. Danes, "Family Financial Socialization: Theory and Critical Review," Journal of Family and Economic Issues, vol. 32, no. 4, p. 644-667, (2011).

[8] N. Tang, A. Baker and P. C. Peter, "Investigating the Disconnect between Financial Knowledge and Behavior: The Role of Parental Influence and Psychological Charateristics in Responsible Financial Behaviors among Young Adults," The Journal of Consumer Affairs, pp. 376-406, (2015).

[9] U. Sirsch, M. Zupanc `ic $`$, M. Poredoš , K. Levec and M. Friedlmeier, "Does Parental Financial Socialization for Emerging Adults Matter? The Case of Austrian and Slovene FirstYear University Students," Emerging Adulthood, pp. 1-12, (2019).

[10] A. N. Faherty, K. Lowe and J. J. Arnett, "Mind games: Parental psychological control and emerging adults' adjustment," Journal of Social and Personal Relationships, pp. 1-20, (2019).

[11] N. Tang and A. Baker, "Self-esteem, financial knowledge and financial behavior," Journal of Economic Psychology, vol. 54, pp. 164-176, (2016).

[12] H. K. Baker, G. Filbeck and V. Ricciardi, "SSRN," 28 May 2017. [Online]. Available: https://papers.ssrn.com/sol3/papers.cfm?abstract_id=2974217. [Accessed 3011 2019].

[13] N. M. Porter, "Testing A Model of Financial Well-Being (Dissertation)," Virginia Polytechnic Institute and State University, Blacksburg, VA, (1990). 